\title{
Low-Temperature Heating Systems Control in Low-Energy Buildings
}

\author{
Vojtěch Mazanec ${ }^{1}$, Karel Kabele ${ }^{2}$, \\ ${ }^{1}$ University Centre for Energy Efficient Building, ${ }^{2}$ Czech Technical University in Prague
}

\begin{abstract}
The paper deals with the control of low-temperature heating systems and their responses to changes in indoor environment with the main focus on indoor environmental quality and real energy savings reflecting low-energy buildings energy needs.

In relation to energy savings, utilization of low-temperature heating systems is increasing today, in connection with lowtemperature heat sources, such as heat pumps. Lower temperature difference between the heating unit and the environment, along with the heat capacity, however, requires better control to be able to make effective response to potential changes in the indoor environment.
\end{abstract}

Keywords - Control, floor heating, low energy buildings, microenvironment

\section{INTRODUCTION}

Energy consumption in buildings is a big issue recently. According to the statistics, building operation in Europe requires up to $40 \%$ of total energy consumption [1], and there is therefore a great potential for savings. Low-energy and passive houses are no longer uncommon or experimental, they have become a normal part of building industry and their application in the market is very wide-spread nowadays. The quality of such buildings doesn't depend only on proper building envelope and preventing the heat loss. Energy system and the ability of the building to effectively control this system in response to external and internal influences also have a significant impact. Even a very good energy system can be ineffective if it cannot respond to the operation of the building appropriately.

\section{A. Low-energy building specifications}

What do we exactly understand by the term "building with low energy consumption"? Present day significance of this topic caused that there are a large number of concepts and definitions. They differ mainly with respect to the requirements to be included and how they are taken into account. But in this article we will mainly deal with the heating systems and their impact on total energy consumption and microenvironment of the object.

Microenvironment of each building is unique and is influenced greatly by the type of building operation, construction of the building, energy supply systems but also the location of buildings and the behavior of the user. The term "low-energy building" is also very wide and includes a number of technologies, processes and construction materials; therefore, it is difficult to generalize. But there are some typical characteristics of indoor environment of such buildings that these object have in common.

\section{B. Low-temperature heating}

The heat loss is the component which raised the issue of low-energy buildings. Most of the energy was consumed to maintain heat in the building, therefore, the initial questions were about the building insulation, impermeability of the envelope and the concept of heating. Although the first two factors mentioned have a significant impact on energy consumption, in this paper we will mainly deal with the heating system and how its control and responses affect its efficiency.

Due to the well-insulated envelope, the use of heating systems with higher temperature gradient becomes less and less efficient. High temperature heaters heat up the room very quickly and it leads to frequent switching of the system which is energetically inefficient. Therefore, there is a greater use for low-temperature heating, which heats in the long term to a lower temperature and thus it can easily adapt to the demands of the insulated building. From the list of low-temperature heating elements, the floor heating, the wall heating and the ceiling heating are the ones that are used most commonly. Large surfaces are used instead of higher temperatures.

Surface heating has its own distinct specifications, especially that it significantly changes the air distribution in the room. High temperature heater located below the window prevents the falling cold currents from getting to the floor and it creates a relatively large area of local thermal discomfort. Currents of warm air, rising up from the body, encounter falling cold currents, turning them and mixing with them. These mixed currents then with an appropriate flow rate and temperature get to the entire room. But if we have a heating surface integrated into some of the inner walls or floor, the cold air falls down without obstacles and slides across the floor with the speed between 0.3 and 0.5 meters per second [2]. Deeper in the room, the air is heated and turns upwards, flows around the inner walls to the ceiling and back to the cooler glass surface. Intense peripheral area of floor heating or a floor convector cannot completely turn this stream away; it can only mitigate it partially and deflect it. The advantage of low energy buildings is obviously better insulation and consequently warmer inner surface of the glazed surfaces, which significantly reduces this effect. But complications occur during ventilation when the air with a very different temperature is let in. 


\section{MEASURED BUILDING}

The measured building is a typical Central-European low-energy terraced house located in the southern outskirts of Prague on the edge of the residential area of the Zbraslav district. The detailed placement of this building can be seen in Fig. 1, where the site plan is shown. This relatively modern building was built in September 2012.

It has two floors, the lower one mainly used for daily living, upper floor is conceived as resting part of the house with bedrooms and bathrooms. Main orientation of the building is to the south - north and most of the living areas are opened to southern side where there is an entrance to a small garden and to a spacious terrace screened by wooden blinds. The total area of the building is 172 square meters with 102 square meters in the ground floor and 70 square meters in the second floor. You can see the ground plans of both floors with room descriptions in Fig. 2.

Most of the bearing walls are from perforated sand-lime bricks with a thickness of 160 millimeters, only the western outer wall is made of monolithic concrete. External walls are insulated with the facade polystyrene boards with a thickness of 160 millimeters and covered with wooden cladding. Due to the use of the floor heating as the only source of heat, all the habitable rooms have wooden flooring and the halls and the corridors have their floor covered with tiles. No air conditioning or any type of mechanical ventilation is installed in the object with the exception of the bathrooms and the utility room.

The building was not permanently inhabited during the measurement and therefore the interior was not furnished. The partial operation of the building was artificially simulated for the individual influences to be more recognizable. The main simulated events were the following: timed natural ventilation, partial ventilation during entering the building, the use of domestic hot water (e.g. for bathing) and the change of the desired interior temperature.

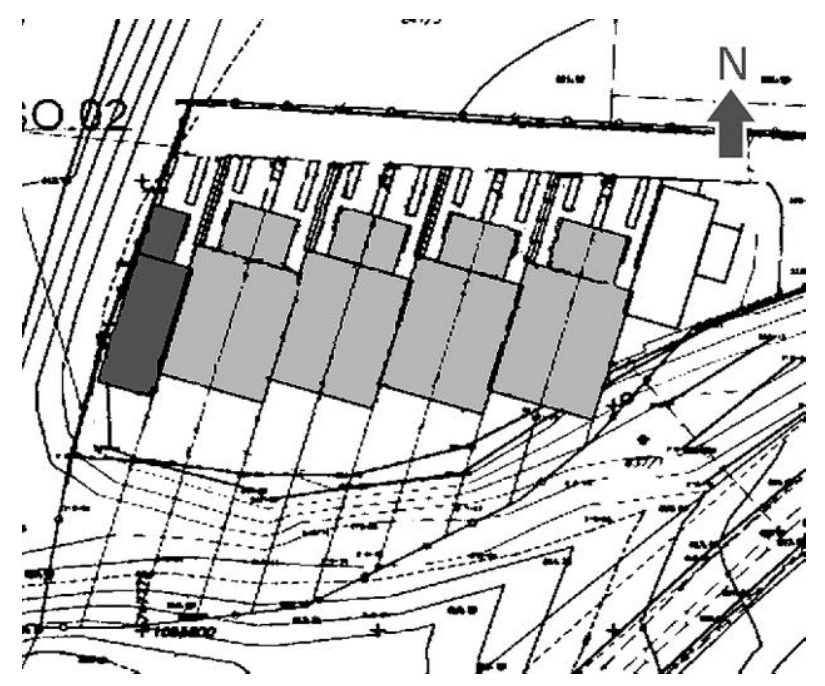

Fig. 1. The situation plan of the terraced houses. Measured building is marked with a dark grey color, located in the western part of the site.

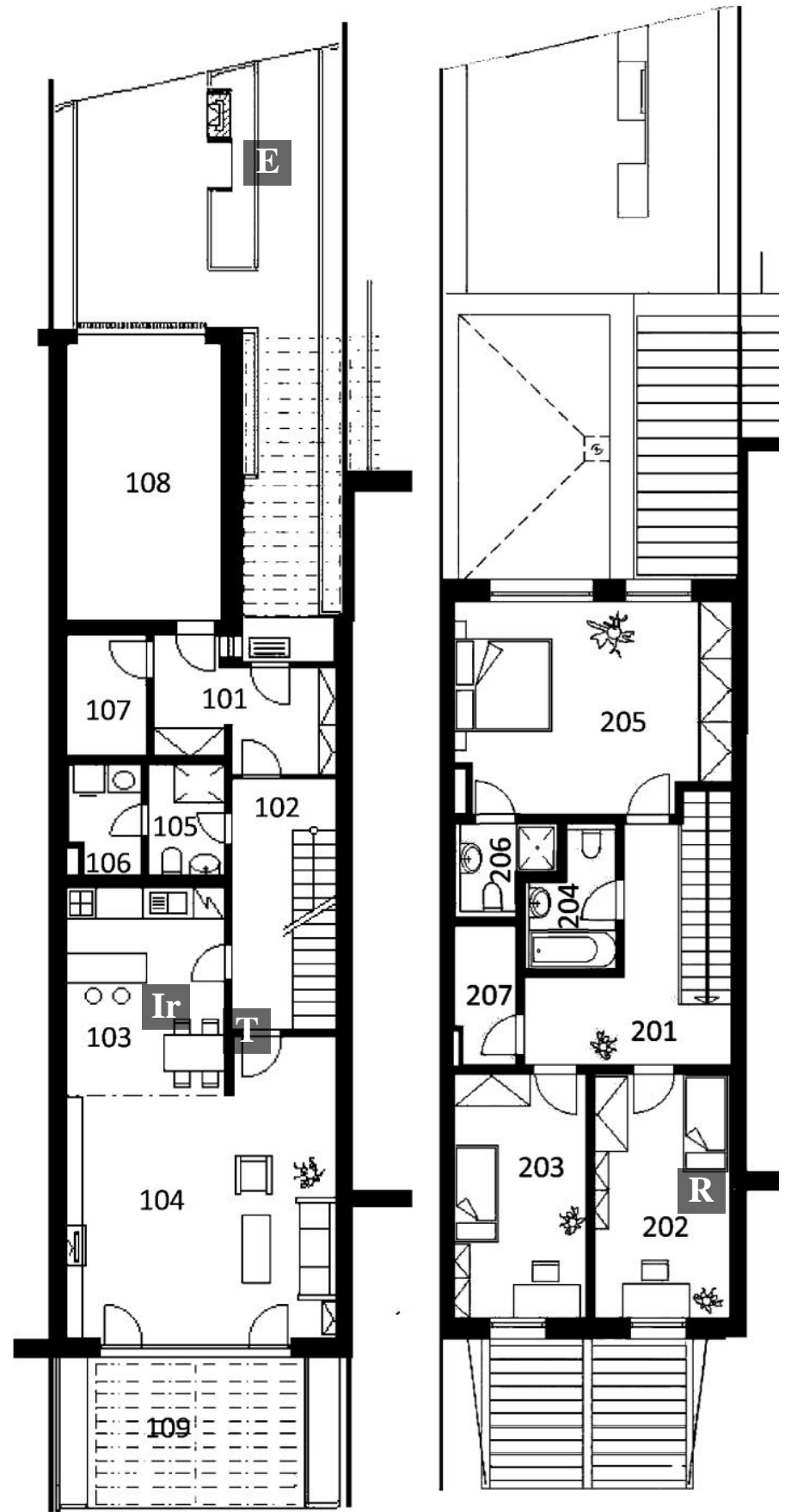

Fig. 2. The ground plan of the measured building.

The first floor (on the left) contains entrance hall (101), corridor (102), living room with kitchen (104 and 103), bathroom (105), utility room with inner heat pump unit and hot water tank (106), store room (107), garage (108), and terrace (109). The second floor (on the right) includes hall (201), two children rooms (202 and 203), bathroom (204), master bedroom (205), master bathroom (206), and store room (207). The locations of the measuring devices are marked by gray boxes: logger near the room thermostat $(\mathrm{T})$, Infra-red sensor (Ir), exterior temperature logger (E) and sensor in the room in the second floor (R). 


\section{SYSTEM AND MEASUREMENTS}

The energy system of the building is based on the air-water heat pump. It is a split unit with exterior unit located on the north side of the site and the indoor unit located in the utility room (Room 106 in the floor plan). This heat pump is used for heating of the building and domestic hot water. The connection of the system is illustrated in Fig. 3.

As it can be seen in the diagram, the inner part of the heat pump is connected via automatically controlled three-way valve leading to the domestic hot water tank and to floor heating distributors in the first and in the second floor. The heating system is controlled according to the exterior temperature and the interior temperature. Temperature of the water tank is kept between $40^{\circ}$ and $48^{\circ}$ Celsius.

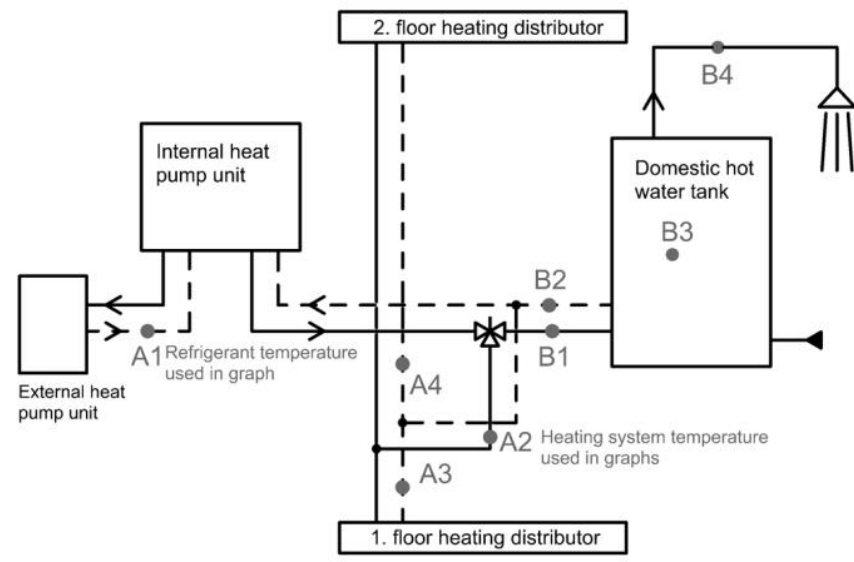

Fig. 3. The diagram of the system connection and the location of temperature sensors.
There are three electric floor heating systems, one in each bathroom, which are separated from the main system. These systems are controlled independently on the central system by the thermostats installed in the bathrooms.

\section{A. Heat pump parameters}

The heat pump has an internal and an external unit at a distance of approximately 15 meters one from each other. Nominal heating capacity (in accordance with EN 14511, water temperature $35^{\circ} / 30^{\circ}$ Celsius, air temperature of $7 \% 6^{\circ}$ Celsius) is 9.1 kilowatts. Minimum heating capacity is 3.6 kilowatts and maximum is 11.1 kilowatts. Nominal COP of the heat pump is 4.2 .

The heat pump has an auxiliary electric heater element with heating capacity 6 kilowatts which is integrated in the indoor unit.

\section{B. System control}

The system is regulated by the control panel located in the first floor in the living room (number 104 in the ground plan). Several sensors are used by the control panel to control the system. The first one is located in the panel, it measures the internal temperature in the living room and is placed approximately at 1.5 meters. The second one measures exterior temperature on the northern facade of the building and it is used for equitherm curve regulation. The third one is in the domestic hot water tank. The main priority of the heating depends on the temperatures in different systems. If the interior temperature is sufficient, priority is given to hot water. The heating system turns the hot water off and focuses on the heating of the building only in the case of drop of the internal temperature. We used the setting of the control panel given by the manufacturer.

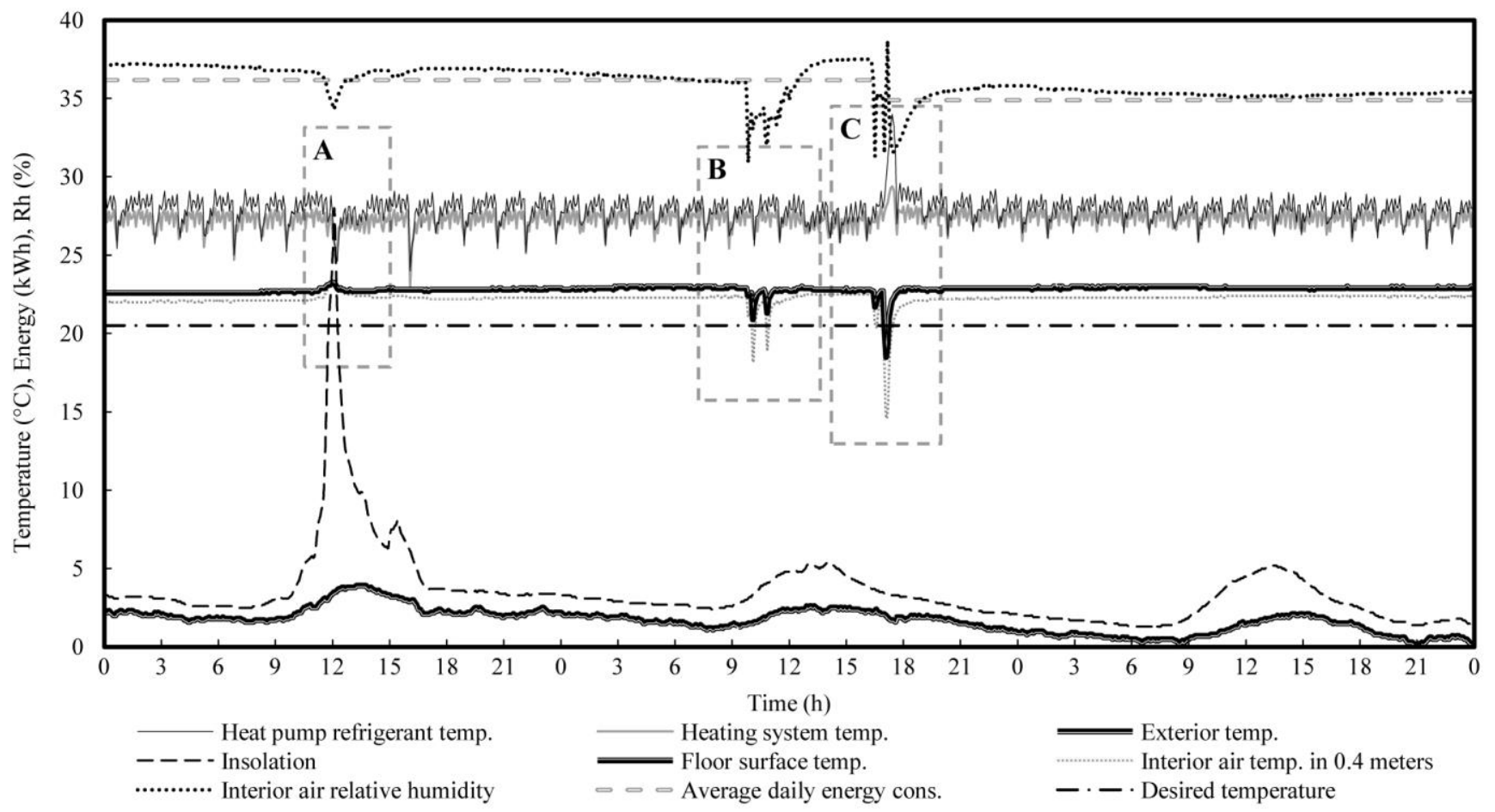

Fig. 4. The graph of the first three-day sample. 


\section{Measuring devices}

To measure the changes in the external factors and the response of the system, we used different types of devices. Two four-channel data loggers were used to measure the temperature of the system. There were eight probes deployed according to the diagram in Fig. 3. Three loggers were used to monitor local temperatures and relative air humidity; one placed close to the control panel in the living room (logger was added after one week of measurement so the first part of the measurement uses only IR probe listed below), one was measuring the external temperature in the shade near the external unit of the heat pump and the position of the last one was varied as required to specify different data. The next device used was infrared thermometer with temperature probe which was 0.4 meters above the floor. We used that device to measure surface temperature of the floor in a spot that was permanently in the shade and where the floor heating was installed.

We were also monitoring the energy consumption of the object, using the device measuring the amount of energy supplied to the object. The sensor was connected to the main electrometer and calculated daily sum of energy delivered to the object. And because the object is not connected to gas or other energy source, electricity covers all the energy losses of the building, although there were some other electrical appliances (pumps, security systems, computer used for data logging, etc.), so not the whole amount of energy was used for heating the object. Average energy demand of the object without the heating was approximately 0.5 kilowatt.

\section{THE MEASURING PROCESS}

We measured the building for about four weeks with different settings and different operations to find out how the system reacts in different situations and various external conditions. We present three three-day samples in this paper in which we can show most of the main experiments. These three-day samples are shown in graphs in Figs. 4, 5 and 6. Particular experiments are highlighted, marked with letters and described bellow in detail.

The first sample (Fig. 4) contains three-day part of the measurement when the domestic hot water heating was turned off. The main objective of this part was to obtain basic information about the performance of heating system to be able to compare it lately with the system in full operation.

In the second three-day sample (Fig. 5) we can see 24 hour period during which the heating system was turned off (highlighted as area E) and the reaction of the system after it was turned on again.

The third measurement sample (shown in Fig. 5) contains system reaction to exterior temperature rising above $4^{\circ}$ Celsius when defrosting cycles of the exterior heat pump unit are no longer needed and there is a system temperature shift according to the equitherm curve. Furthermore, there is a 24 hours period where the desired interior temperature was set to $24^{\circ}$ Celsius.

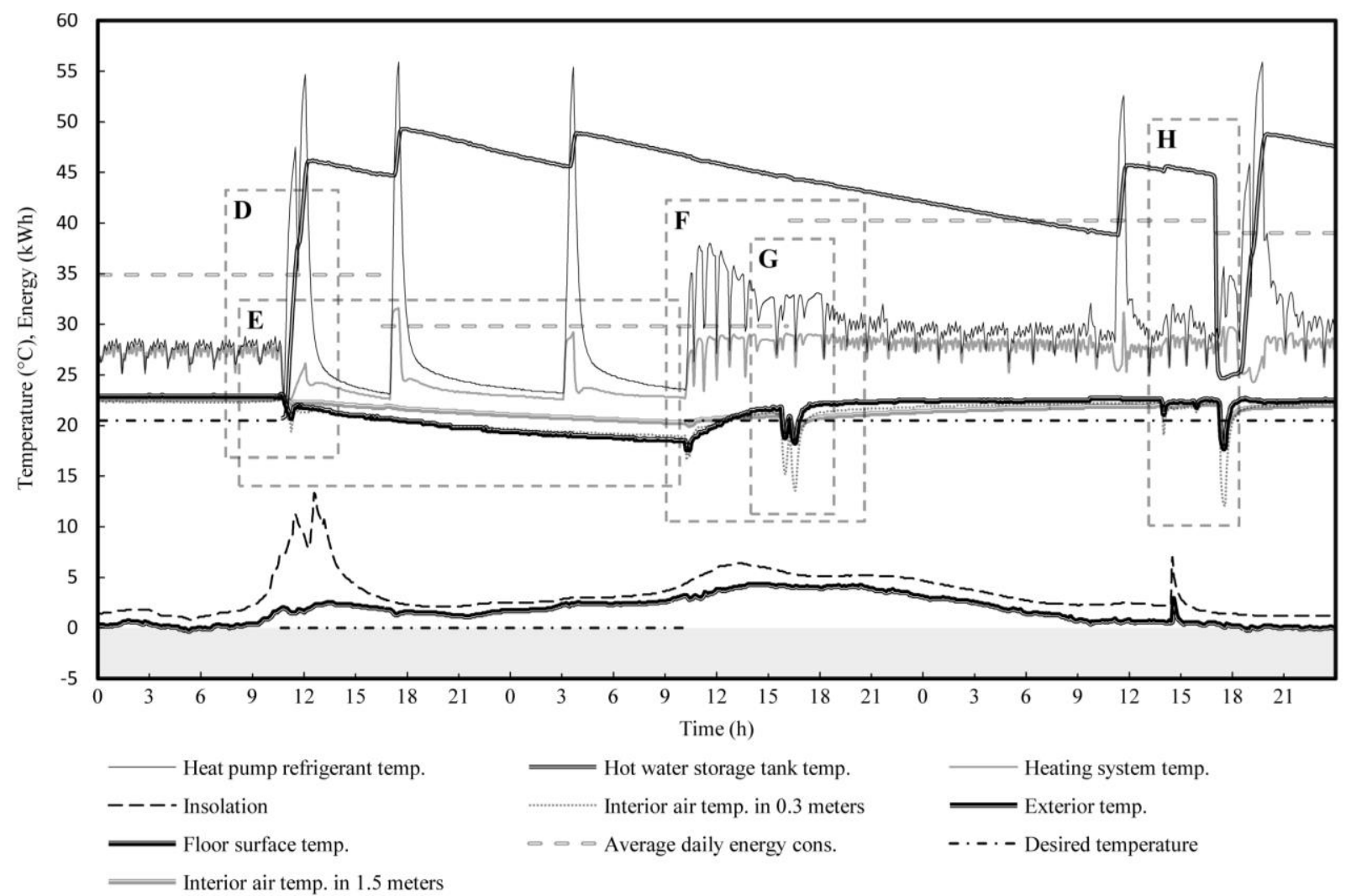

Fig. 5. The graph of the second three-day sample. 


\section{EXPERIMENTS}

At first we have to point out that the temperature control is not very accurate when keeping the desired interior temperature. While the thermostat is set to $20.5^{\circ}$ Celsius, the room temperature ranges between $22^{\circ}$ and $23^{\circ}$ Celsius at the height of the thermostat. This difference has a negative effect on both thermal comfort and the total energy loss of the object. The problem is probably caused by the temperature setting range and/or by the inaccuracy of the built-in measuring device of the thermostat.

\section{A. Response to solar gains}

The first experiment (marked as highlighted area A) shows the response to significant solar gains. When the interior air temperature reaches $23^{\circ}$ Celsius, the heating system is turned off and it starts again when the temperature drops below this line. We can see that the solar radiation in that scale can even heat up the water in the floor heating which is not a problem in winter months but it may have negative consequences during the transitional or summer periods.

\section{B. Short time ventilation}

The second experiment shows entering and exiting the living room to the garden terrace, which means opening the French door for a few minutes (it cannot be fully closed from the outside). We can see the rapid drop of the inner temperature but it is not long enough to get any system reaction. Still, the temperature needs fifteen minutes after windows are closed to return to the previous state.

\section{10 minutes of natural ventilation}

In the third experiment, we simulated natural ventilation for ten minutes. As mentioned, building does not have mechanical ventilation installed, so there is a need for periodical windows opening to exchange indoor air. We can see a drop of indoor air temperature about minus $5^{\circ}$ Celsius at the height of 0.4 meters above the floor. The system reacts almost immediately and it takes about half an hour for the compensation above $20^{\circ}$ Celsius to take place. In addition, it is very important that after the temperature compensation, there is no overheating of the interior.

\section{Change of settings}

At 10:50 AM of the first day in the second three-day sample (Fig. 5.) the setting of thermostat was changed. We switched the heating of the building off and set the domestic hot water on (max. temperature was set to $45^{\circ}$ Celsius). In addition, the windows were opened for a short time period to see how the interior temperature reacts.

We can see the raise of refrigerant temperature with almost no influence on the heating system and we can almost immediately see the rise of the temperature in the water storage tank. The drop of the floor temperature caused by the ventilation was largely compensated by the thermal inertia of the floor heating. The thermal drop of the interior air is only about $0.3^{\circ}$ Celsius and it remained above $22^{\circ}$ Celsius for the next six hours.

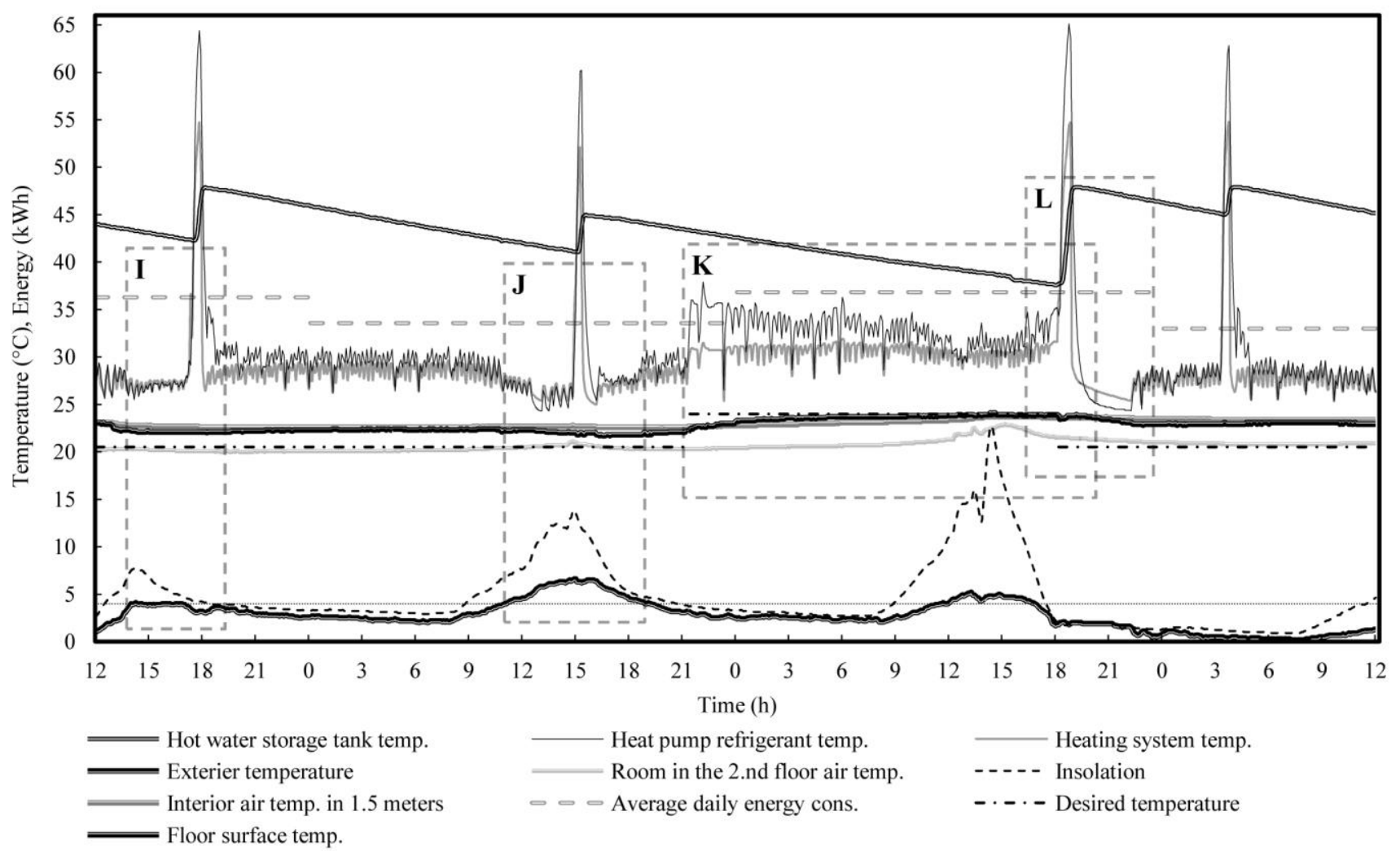

Fig. 6. The graph of the third three-day sample. 


\section{E. Operation without heating}

This experiment was focused on how low the interior temperature drops in 24 hours without heating and what is the impact to the energy consumption. Hot water heating was turned on, so we could compare results with another regular day. After 24 hours, the temperature in the living room dropped by about minus $4^{\circ}$ Celsius near the floor (to value $18.7^{\circ}$ Celsius) and by about $2^{\circ}$ Celsius to value $22.5^{\circ} \mathrm{Celsius}$ in the height of the control panel. At that time the exterior temperature was approximately $1.9^{\circ} \mathrm{Celsius}$. So we can see that the inner temperature is very stable even if the outdoor temperature is quite low.

Looking at the energy consumption, we can find that even together with the energy necessary to re-heat the interior back we still need about 5 kilowatt hours less than on another comparable day and almost 10 kilowatt hours less than on an average day. This experiment shows that we can probably use heating intermissions in order to reduce the overall energy consumption of the building.

\section{F. Reheating the building}

In experiment $\mathrm{F}$ we measured the time needed to reheat the building back to the desired temperature. We can see the significant activity of the heat pump which heats the water in the system relatively quickly to the required temperature and when the interior temperature rises above the desired level (20.5 Celsius), it gradually returns to the previous stable mode.

The main difference in comparison with short time ventilation is the time required to get the temperature back above $22{ }^{\circ}$ Celsius. It took another 24 hours to reheat the mass of walls. In comparison with the experiment $\mathrm{C}$ it was only 90 minutes.

\section{G. Ventilation during the temperature raise}

We tried to measure the difference between the ventilation in the stable conditions and the ventilation in more significant activity of the heating system. There is no difference in reactions, but we can see the difference at various heights. The temperature drop of the interior air at the height of 1.5 meters is more like the drop of the floor surface temperature and almost half of the temperature drop at the height of 0.4 meters, but in contrast the rise is more similar to the one that is at the height of 0.4 meters.

\section{H. Water drain and ventilation}

In this experiment we simulated the combination of longer ventilation and hot water drain needed for filling the bath-tub. It shows the priority setting of the system. We can see that the heating of the hot water started after the interior temperature rose above the desired value. But it was not done immediately after that. The system waited till one heating cycle (and one defrosting cycle) was completed.

It may be a problem because it took almost 2 hours (110 minutes) before the water in the tank was heated again. This is quite uncomfortable, especially in the daily regime of the family which expects merging those activities (ventilation and washing) during the short evening period.

\section{Equitherm reaction}

The experiment I shows the reaction to the change of the exterior air temperature above the threshold of $4^{\circ}$ Celsius. The heat pump operation mode was changed abruptly, but that short period did not have significant impact on any measured values.

\section{J. Equitherm reaction II}

The second reaction to the exterior temperature rise was longer and more significant. There was a drop of the heating system temperature by almost $5^{\circ}$ Celsius and in reaction we can see the decrease of the floor temperature.

If we compare the results with other similar days, we can say that it has a positive effect on the energy consumption of the building. But in comparison to experiment E, we would probably get the same (maybe better) effect if the heat pump was not started for the same time period.

\section{K. Change of the desired temperature}

In this experiment we tried to figure out how the system responds to user requests. We set up the desired temperature on the control panel to $24^{\circ}$ Celsius and measured the time needed to heat the interior to that value.

As we can see, it takes more than 18 hours to reach it, which is extremely uncomfortable. This problem is caused by system setting which does not allow changing the temperature of the floor heating surfaces significantly. While being set up to $20.5^{\circ}$ Celsius, the system uses floor surface temperature of about $23^{\circ}$ Celsius with quick result. Setting up the thermostat to $24^{\circ}$ Celsius causes a gradual increase of the floor heating temperature to $24^{\circ}$ Celsius. It is understandable that with such a low temperature difference the heating of the interior takes a long time.

The second problem is that during that time the priority was set to heating and the system did not heat the domestic hot water, so the temperature of the hot water tank dropped to $37^{\circ}$ Celsius.

\section{Drop of the system temperature}

After setting the thermostat back to $20.5^{\circ}$ Celsius, the system immediately heated up the domestic hot water. Then the heat pump was switched off until the temperature of the floor surface did not drop below $23^{\circ}$ Celsius and then the system switched to the standard mode. From that point interior temperature remained above the line of $23^{\circ}$ Celsius for more than 24 hours. 


\section{CONCLUSION}

We measured the heating system of the building and recorded responses to various external influences. From the local experiments we traced the basic elements of the behavior of this system and we tried to analyze their causes and consequences. This analysis suggests several key conclusions.

\section{A. Ventilation}

We can conclude from the previous experiments that ventilation is one of the major questions connected to several problems. Missing mechanical ventilation requires a natural ventilation of the building but longer period of ventilation has significant effect on other parts of the system. It affects the overall energy consumption and it partially suspends the heating of the domestic hot water. The user should use shorter ventilation periods, but it is important to ensure sufficient air exchange in the building.

\section{B. Interior temperature}

The system of the building is well balanced to maintain one interior temperature for a long time periods, although there are some complications caused by a scatter of measuring devices or by setting of the system which causes difficulties when choosing the right interior temperature. Specifically, the system setup allows the interior to overheat above the desired temperature which also has an impact on the energy consumption of the building but also on the thermal comfort inside the building.

But the system has a problem with changing a desired temperature. Heating up the interior takes extremely long time and it can be uncomfortable for the users. It is probably caused by the control settings of the system.

The last difficulty is the thermal imbalance of the two floors, because the second floor temperature is typically about two degrees Celsius lower than the ground floor temperature.

\section{Heating intermissions}

The use of longer breaks in the heat pump operation for heating could have great importance for the overall energy balance. Experiments show that the thermal inertia of the object is sufficient to sustain relatively stable interior temperature even during longer time periods without heating. It could have a positive impact on the energy consumption and also on the heat pump service life.

\section{Thermostat height}

The height of the thermostat above the ground could also be a complication. Air currents have specific behavior in rooms with floor heating, as mentioned in the paper introduction. In case cold air caused by short natural ventilation remains near the floor, the thermostat will not detect the change of the temperature and heating system will not start. It may cause a large difference in temperature and local temperature discomfort.

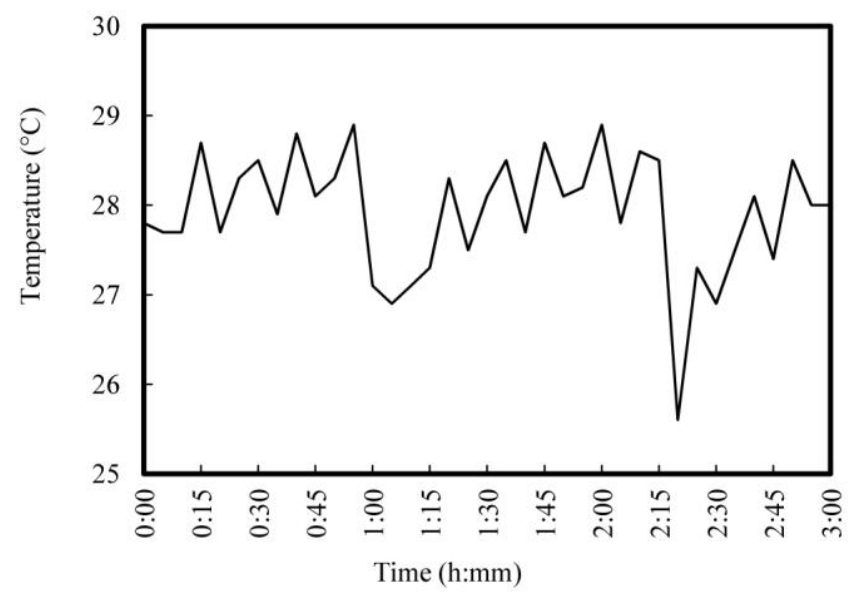

Fig. 7. The frequency of the heat pump switching.

\section{E. Frequency}

The last thing necessary to deal with is the high frequency of switching the heat pump on and off. The heat pump is switched on and off five times in one hour to maintain the temperature of the heating system in the range $1^{\circ}$ Celsius. But there is $5^{\circ} \mathrm{Celsius}$ difference between the water in the system and the floor heating surface. The water returning from the floor heating is almost as warm as the water leaving the heat pump. This rapid switching frequency, however, has a negative effect on the compressor and on the service life of the heat pump.

\section{ACKNOWLEDGEMENT}

The authors wish to thank for financial support the European grant OP VaVpl No. CZ.1.05/2.1.00/03.0091 University Centre for Energy Efficient Buildings.

\section{REFERENCES}

[1] The Directive 2010/31/EU of the European Parliament and Council of 19 May 2010 on the energy performance of buildings, Official Journey of the European Union, 53, 2010.

[2] "Otopná plocha a ovlivnění parametrů vnitřního prostředí," Nov. 1, 2002. [Online]. Available: http://www.tzb-info.cz/1186-tzb2002-otopna-plocha-a-ovlivneni-parametru-vnitrniho-prostredi [Accessed: Dec. 6, 2015].

[3] Building certification, www.gresb.com

[4] Kabele, K. - Bartoňová, J. - Patakiová, M. - Vavřinová, K. Simulation in Control System Sensor Location Design In: Proceedings of the 12th Conference of The International Building Performance Simulation Association.. Sydney: IBPSA Australasia, 2011, p. 2573-2578. ISBN 978-0-646-56510-1.

[5] Kabele, K. National Calculation Tool for EPBD Energy Performance Certification In: Instalatorul. 2009, vol. XVII, no. 5, p. 56-57. ISSN 1223-7418.

[6] Kabele, K. - Urban, M. Energy performance simulation in building certification process In: 40th INTERNATIONAL CONGRESS ON HEATING, REFRIGERATING AND AIR - CONDITIONING. Beograd: KGH, 2009, p. 42-52. ISBN 978-86-81505-50-2. 